\title{
IS THERE ANY RELATIONSHIP BETWEEN FLUCTUATING ASYMMETRY AND REPRODUCTIVE INVESTMENT IN GIANT FEATHERBACK (CHITALA LOPIS, NOTOPTERIDAE)
}

\author{
Arif Wibowo \\ Research Institute for Inland Fisheries, Mariana, Palembang, Indonesia. \\ Received June 1-2012; Received in revised form December 17-2012; Accepted December 18-2012 \\ E-Mail:wibarf@yahoo.com
}

\begin{abstract}
:
Fluctuating asymmetry (FA) is often used as an indicator of perturbed development. As organisms placed under greater stress, less energy is available to buffer their development compared to unstressed individuals and increasing levels of asymmetry. Therefore, individual asymmetry scores within a population can be used as a measure of an organism's ability to buffer its development and can be considered as an indirect measurement of individual fitness. In this study a test was conducted to know any correlation among FA and four fitness traits in giant featherback (Chitala lopis) inhabiting non acidified and acidified region along the Kampar River. Three bilateral meristic characters were counted on each side of the fish: number of gill rakers on the lower first branchial arch, eyes diameter, and number of pectoral-fin rays and four traits related to the fitness were measured: egg diameter, size of first maturity, gonad somatic index, and fecundity. Results show that FA (both number and magnitude) levels are differerent, giant featherback inhabiting more acidic station were slightly more asymmetric than those from less acidic one except to those inhabiting alkali station. However, the reproductive investment of giant featherback in the five sampling stations studied here gave no indication that the populations strongly affected by acidification. In this study it did not find any significant negative correlation between FA and any of the measured fitness traits. Therefore it can be concluded that FA is not a useful measure of fitness in this species.
\end{abstract}

Keywords: Fluctuating asymmetry, chitala, reproductive investment

\section{INTRODUCTION}

Fluctuating asymmetry (FA) is a population parameter that measures random deviation from perfect symmetry in bilaterally symmetric traits. Fluctuating asymmetry is important to population biologists because it reflects a population's state of adaptation and co adaptation. FA is often used as a measure of developmental stability (Van Valen, 1962). In an ideal, stress-free environment, bilaterally symmetric characters (e.g. right vs. left arms in humans) would be produced that are morphometrically identical. In reality, no such system exists, as there will always be some elements of randomness in an organism's development, resulting in asymmetry (Moller \& Swaddle, 1997).

Developmental stability therefore relates to the capacity of an organism's developmental pathways to resist accidents and perturbations during the growth process (Moller \& Swaddle, 1997). Normally, small perturbations during development are corrected by stability mechanisms, however when stressed, developmental mechanisms that buffer against the expression of asymmetric characters may break down, leading to the production of deviant phenotypes (Clarke, 1995).
In using $F A$, the underlying assumption is that development of the two sides of a bilaterally symmetric organism are controlled by an identical set of genes and therefore any non directional differences between the sides must be environmental in origin (Waddington, 1942). It has been argued that individuals with a high level of developmental stability have a selective advantage over individuals with lower developmental stability, and therefore developmental stability has been viewed as an integral component of individual fitness (Møller \& Swaddle, 1997). The relationship between asymmetry and fitness has been extensively reviewed (Clarke, 1998; Møller, 1999), and several studies have reported a correlation between individual symmetry and fitness components such as fecundity and growth. Positive correlations between FA and environmental stresses have also been observed in various aquatic studies (Alados et al., 2001).

In fish, individual and population levels of bilateral asymmetry have been shown to relate positively to a wide range of abiotic, biotic and genetic stresses. Abiotic factors such as acidification, toxic chemicals or heavy metals are common stressors which produce elevated levels of FA (Allenbach et al., 1999; Estes et al., 2006). The individual fitness of freshwater fish exposed to acidification (reduced $\mathrm{pH}$ and increased level of inorganic monomeric aluminium) is weaked 
because of reduced growth and decreased survival probability. When acidification is sufficiently strong, population effects are evident (Hesthagen et al. 1999). Asymmetry usually increases under environmental stresses because of the failure of the homeostatic regulatory mechanism (Bengtsson \& Hindberg, 1985). However, at lower intensities it may be difficult to detect these population responses. FA may be an early indicator of such an acidification process, as well as of a number of other environmental disturbances (Leary \& Allendorf, 1989; Sommer, 1996).

In general, it suggests that giant featherback inhabiting acidified river are more asymmetric than those from non-acidified lakes. However, to use this variation in morphological asymmetry as a tool for conservation biological purposes it is necessary to document the association of morphological characters with individual fitness. If FA is correlated with fitness in giant featherback, it expect this correlation to be more pronounced and more easily detected in acidified river than in those in non-acidified river, owing to the larger expected variation in FA in giant featherback from acidified river. In this study, therefore, a test was conducted to know if FA is correlated with a number of fitness related traits (reproductive investment) in giant fetaherback from variety acidification status.

\section{MATERIALS AND METHODS}

Five sampling stations selected in Kampar River, Riau Province, which are vary in the level of acidification and there are no known local sources of pollution The water $\mathrm{pH}$ was checked in each sampling station using portable $\mathrm{pH}$ meter. These five sampling stations are:

Station I : Kutopanjang (GPS 00019'5,39" N, 100 44'3,79" E).

Station II : Teso (GPS 0003'2,34" N, 101023'2,71" E).

Station III : Langgam (GPS 00015'4,69" N, $\left.101^{\circ} 42^{\prime} 4,55^{\prime \prime} \mathrm{E}\right)$.

\section{Station IV : Rantau Baru (GPS 00017'1,06" N, 101048'1,22" E). \\ Station V : Kuala Tolam (GPS 00019'3,10" N, $\left.102^{\circ} 11^{\prime 2} 2,60 " \mathrm{E}\right)$.}

Giant featherbacks were sampled from late May 2009 until early November 2010 using some kind scope nets, fish traps and fishing line. In total, 84 individuals were captured (Table 1).

Table 1. The number of individual for each sampling station

\begin{tabular}{clc}
\hline No & \multicolumn{1}{c}{ Sampling Station } & $\begin{array}{c}\text { Number } \\
\text { individual }\end{array}$ \\
\hline 1 & Kutopanjang Reservoir & 16 \\
2 & Teso & 14 \\
3 & Langgam & 12 \\
4 & Rantau Baru & 25 \\
5 & Kuala Tolam & 17 \\
\hline & Total samples & $\mathbf{8 4}$ \\
\hline
\end{tabular}

The calculation of gonad somatic index was estimated as 100 (gonad mass/somatic mass). Gonad wet mass was measured with an accuracy of $0.01 \mathrm{~g}$. For estimating fecundity, three subsamples (anterior, posterior and middle) of gonad were taken from each fish. Each subsample was weighed and then preserved in $70 \%$ ethanol. The eggs in each of the three subsamples were then counted per gram of wet gonad mass was used to estimate absolute fecundity (Effendie, 1979). A sample of 100 eggs was subjected to diameter measurement. Sperman Karber methods were used (King, 1985) to estimate the fish's size of first maturity.

Pectoral fins and first gill branchial arches were dissected from the fish, cleaned and dried, and examined using a dissecting microscope. Three characters were counted on each side of the fish: number of gill rakers on the lower first branchial arch, eyes diameter and number of pectoral-fin rays (Figure 1). 


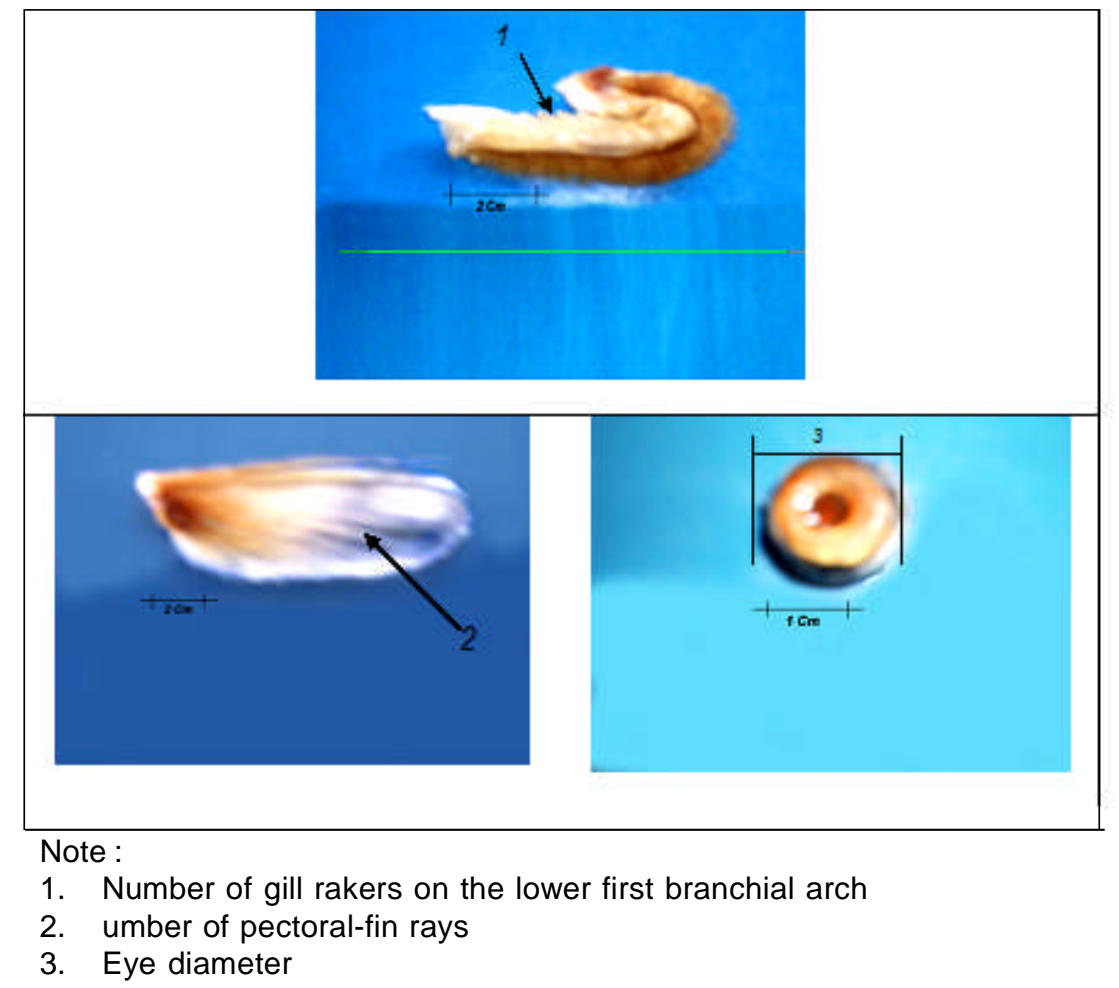

Figure 1. Observed fluctuation asymmetry characters

Paired measurements were entered for each individual and transformed into signed asymmetry values according to the formula right-left. All the calculation were subject to estimate both the value of fluctuation asymmetry magnitude and number according to formulation by Leary et al. (1983):

$$
\begin{aligned}
& \text { FAn } \neq \frac{\sum(\mathrm{L}-\mathrm{R})}{\mathrm{N}} \\
& \mathrm{FAn}=\frac{\sum \mathrm{Z}}{\mathrm{N}}
\end{aligned}
$$

\section{Where :}

$\mathrm{FAm}=$ Fluctuation asymmetry magnitude

Fan = Fluctuation asymmetry number

$L \quad=$ Number of left's organ

$\mathrm{R}=$ Number of right's organ

$Z=$ Number of asymmetry for certain characters.

$\mathrm{N}$ = Sample number

Multiple linear regressions were applied in STATISTICA 6.0 Package to test correlations between FA and fitness traits as described by øxnevald et al. (2002). The fitness parameters were fecundity, GSI, egg diameter, and gonad mass.

\section{RESULTS}

The $\mathrm{pH}$ of sampling station in this study exhibit variation, Figure 2, showed a gradual decreasing of water $\mathrm{pH}$ from upstream to downstream in Kampar River.

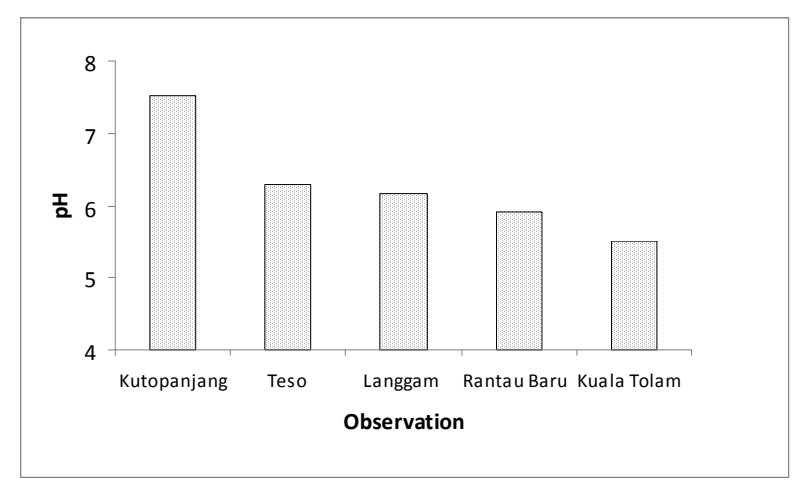

Figure 2. The value of water $\mathrm{pH}$ of sampling stations

There were differences in total FA among giant featherback from five sampling stations both for number and magnitude (Figure 3 ). 


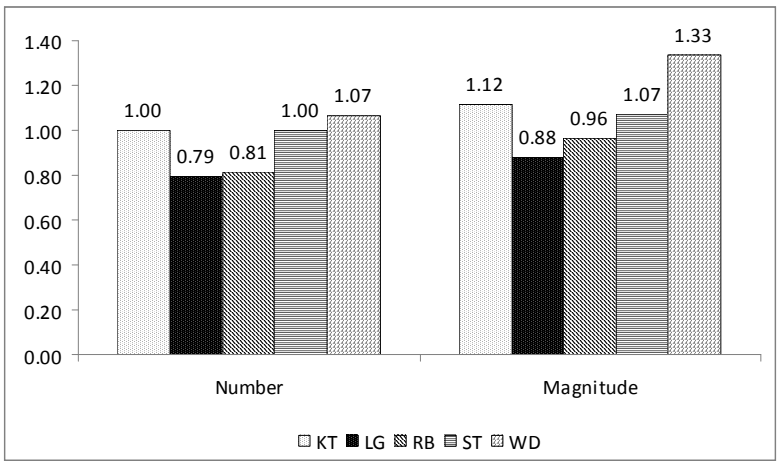

Figure 3. The value of overall Index of fluactuating asymmetry
The giant featherback in this study also exhibit variation in fitness trait examined (Figure 4). Egg diameter and gonad somatic index characters found that the fish from Kuala Tolam showed the highest level in fecundity than those fish in Teso and Langgam. This population also has the smallest size of the first maturity.

There was a correlation between FA and the minimum size of fish maturity and there was no correlation among FA and gonad mass, egg diameter or fecundity (Table 2). However, when it performed 40 individual multiple regressions ( 5 sampling stations $x$ 2 charcaters FA $x 4$ fitness parameters) using fitness trait as the dependent variable and FA estimate as independent variables, in non of the multiple regressions was find a significant FA effect (all P > 0.05).

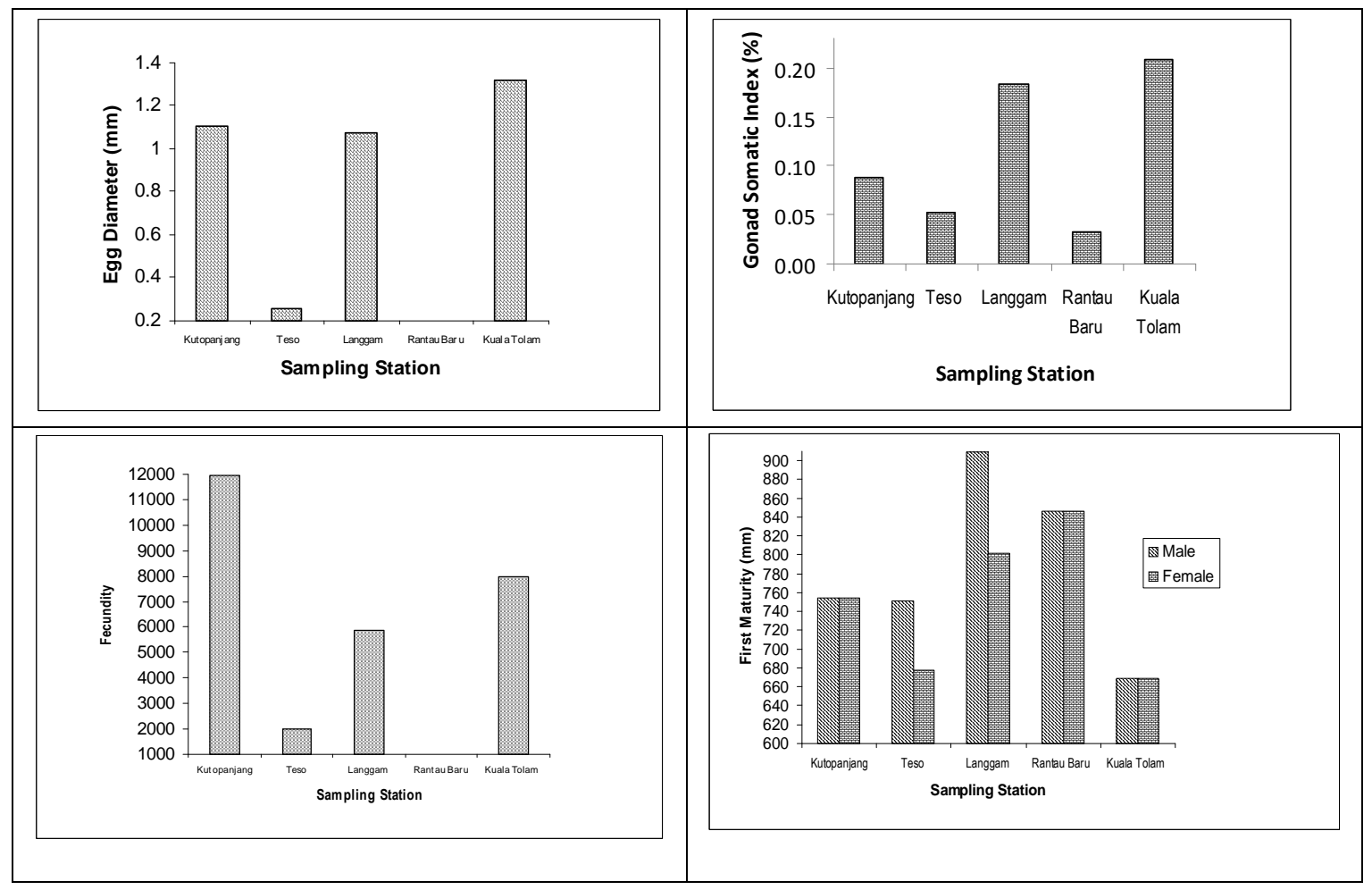

Figure 4. Reproductive investments of giant featherback

Table 2. Correlation between FA and fitness trait

\begin{tabular}{lcccccc}
\hline & Number & Magnitude & $\begin{array}{c}\text { Gonad } \\
\text { somatic index }\end{array}$ & $\begin{array}{c}\text { Egg } \\
\text { diameter }\end{array}$ & Fecundity & $\begin{array}{c}\text { Size of the } \\
\text { first maturity }\end{array}$ \\
\hline Number (FA index) & 1.000 & 0.920 & 0.049 & -0.082 & 0.399 & -0.827 \\
Magnitude (FA index) & 0.920 & 1.000 & 0.111 & 0.225 & 0.761 & -0.585 \\
Gonad somatic index & 0.049 & 0.111 & 1.000 & 0.788 & 0.213 & -0.237 \\
Egg diameter & -0.082 & 0.225 & 0.788 & 1.000 & 0.769 & 0.072 \\
Fecundity & 0.399 & 0.761 & 0.213 & 0.769 & 1.000 & 0.003 \\
Size of the first maturity & -0.827 & -0.585 & -0.237 & 0.072 & 0.003 & 1.000 \\
\hline
\end{tabular}




\section{DISCUSSION}

This work shows that FA (both number and magnitude) levels differ between giant featherback populations inhabiting vary acidified environment, the sampling stations were either non-acidified or affected differently by acidification. The result of the study was that giant featherbacks inhabiting more acidic sampling site were slightly more asymmetric than those from less acidified sampling, an exception made on those inhabiting alkali environment. However, studies on the reproductive investment of the fish in the five sampling station studied here give no indication that the populations are strongly affected by acidification. This study confirms oxnevald et al. (2002) opinion's that there is no connection between FA and reproductive investment in animal organism.

Since FA was higher in the more acidic sampling station than in the less acidic one, FA might function as an early-warning signal. However, to be a reliable estimator of population viability, FA needs to be correlated with some fitness trait such as reproductive investment, fecundity, or egg size, but it found no such correlation. It almost found the possibility such as relationship in acidified station, where the possibility is better, it was find a non significant negative relationship between FA and fitness-related traits. There are at least two possible explanations for this. The first is that there is a nonlinear relationship between FA and fitness-related traits, which is only evident at high asymmetry values. The second explanation is that there is, in fact, no relation between FA and the fitness related traits measured (øxnevald et al., 2002).

In general, giant featherback living in more acidic station were more asymmetric than those living in less acidic station. A few other studies have reported on the relationship between FA and fitness in fish. Sasal \& Pampoulie, (2000) studied FA and fecundity in the gobid species Pomatoschistus microps. They correlated pectoral-fin asymmetry in nesting males with the number of eggs in the nest and the density of eggs. They found no significant correlation between FA and male fitness. Downhower et al. (1990) measured otolith asymmetry and fecundity in the sculpin Cottus bairdi at eight localities in Montana and Ohio, USA. They found that otolith asymmetry was negatively correlated with egg number and egg mass. However, the power of this analysis is questionable, since no details of the statistical treatment are given.

In this study, although there was a negative correlation between the size of first maturity and FA, however the result it self was not significant. Thus it might be that the environmental stress experienced in the acidified station studied here is insufficient to produce strong asymmetry, and that the relationships between asymmetry and fitness traits are only evident at such higher stress levels. Further, it also seems that acidification stress has to be strong to induce strongly asymmetric morphology in fish (øxnevald et al., 2002). It is apparent from the literature that organismal developmental stability can be impaired through exposure to chemical pollutants and these stressors can result in an increase in fluctuating asymmetry. For example, some authors (Ames et al. (1979); Zakharov (1981); Jagoe and Haines (1985)) all found increased levels of fluctuating asymmetry in fish species inhabiting ponds with high concentrations of mercury and/or low pH. A number of studies do report only weak or no effects of relatively strong acidification on asymmetry (Wiener \& Rago, 1987; Vøllestad \& Hindar 1997, 2001).

It may also be the case that asymmetry in general is not correlated with fitness traits (øxnevald et al. 2002). In a literature survey, Møller, (1999) presented the estimates of the magnitude and robustness of the relationship between asymmetry and three fitness components: growth, fecundity, and survival. However, the mean correlation coefficients were relatively small and accounted only for $12.3 \%$ of the variance in fecundity. The conclusion from Møller's study is that asymmetry is generally negatively correlated with fitness components. However, earlier reviews and commentaries were contradictory (Clarke, 1995, 1998; Møller, 1997, 1999). What is evident, however, is that in order to use asymmetry as an indicator of the viability of a population or the fitness of an individual, the causal relationship between asymmetry and the fitness trait has to be documented. In this study on giant featherback it did not find a negative correlation between FA and any of the measured fitness traits. It therefore concluded that FA is not a useful measure of fitness in this species.

These results do not imply that FA is an unreliable technique in assessing population stress, but speak to the difficulty in selecting traits that are not highly canalized, and are also under development when the stressor(s) affecting the population is being applied. Therefore, the usefulness of fluctuating asymmetry as a conservation tool is dependent upon the identification of such traits, and should be limited to cases where the agent causing the stress or reduction in population numbers has the opportunity of affecting a species' physiology during development of the trait under study so it can be manifested in the organism's morphology. However, under the right circumstances, 
fluctuating asymmetry monitoring techniques may prove to be very reliable.

\section{CONCLUSION}

There are FA (both number and magnitude) levels differerence, giant featherback inhabiting more acidic sampling site were slightly more asymmetric than those from less acidified sampling. However, it did find any non significant negative relationship between FA and fitness-related traits. It is therefore concluded that FA is not a useful measure of fitness in this species.

\section{ACKNOWLEDGEMENTS}

Thanks to Subagja and Dwi Atminarso for their kind help during the field and laboratory work. The study was supported financially by a grant from the Research Institute for Inland Fisheries Fy 2009 and 2010 budgets.

\section{REFERENCES}

Alados, C.L. T. Navarro, J. Escós, B. Cabezudo \& J.M. 2001. Translational and fluctuating asymmetry as tools to detect stress in stress-adapted and nonadapted plants. Int. J. Plant Sci. 162: 607-616.

Allenbach, D.M., K.B. Sullivan \& M.J. Lydy. 1999. Higher fluctuating asymmetry as a measure of susceptibility to pesticides in fishes. Environ. Toxicol. Chem. 18: 899-905.

Ames, L. J., J. D. Felley, \& M. H. Smith. 1979. Amounts of asymmetry in centrarchid fish inhabiting heated and nonheated reservoirs. Transactions of the American Fisheries Society. 108: 489-495.

Bengtsson B.E \& M. Hindberg. 1985. Fish deformities and pollution in some Swedish waters. Ambio. 14: 32-35.

Clarke, G.M. 1995. Relationships between fluctuating asymmetry and fitness: how good is the evidence? Pac. Conserv. Biol. 2: 146-149.

Clarke, G.M. 1998. Developmental stability and fitness: the evidence is not quite so clear. $A m$. Nat. 152: 762-766.

Downhower, J.F., L.S. Blumer, P. Lejeune, P. Gaudin, A. Marconato \& A. Bisazza. 1990. Otolith asymmetry in Cottus bairdi and C. gobio. Pol. Arch. Hydrobiol. 37: 209-220.
Effendie, M.I. 1979. Fisheries Biology Methods. Yayasan Dewi Sri. Bogor. (in Bahasa Indonesia). $112 \mathrm{p}$.

Estes, E.C.J., C.R. Katholi \& R.A. Angus. 2006. Elevated fluctuating asymmetry in eastern mosquitofish (Gambusia holbrooki) from a river receiving paper mill effluent. Environ. Toxicol. Chem. 25: 1026-1033.

Hesthagen, T., I.H. Sevaldrud \& H.M. Berger. 1999. Assessment of damage to fish populations in Norwegian lakes due to acidification. Ambio, 28: 112-117.

Jagoe, C. H. \& T. A. Haines 1985. Fluctuating asymmetry in fishes inhabiting acidified and unacidified lakes. Canadian Journal of Zoology. 63: 130-138.

King, M. 1995. Fisheries Biology. Assesment and Management. Fishing News Books, Blackwell Science Ltd. $341 \mathrm{p}$.

Leary, R.F., F.W. Allendorf \& K.L. Knudsen. 1983. Developmental stability and enzyme heterozygosity in rainbow trout. Nature (Lond.). 301: 71-72.

Leary, R.F., \& F.W. Allendorf. 1989. Fluctuating asymmetry as an indicator of stress: implications for conservation biology. Trends Ecol. Evol. 4:214-217.

Møller, A.P. 1997. Developmental stability and fitness: a review. Am. Nat. 149: 916-932.

Møller, A.P. 1999. Asymmetry as a predictor of growth, fecundity and survival. Ecol. Lett. 1: 149-156.

Møller, A.P., \& Swaddle, J.P. 1997. Asymmetry, developmental stability, and evolution. Oxford University Press, Oxford. 291 p.

Øxnevad, S.A., E. Heibo, \& L.A. Vøllestad. 2002. Is there a relationship between fluctuating asymmetry and reproductive investment in perch (Perca fluviatilis)?. Can. J. Zool. 80: 120-125.

Sasal, P \& C. Pampoulie. 2000. Asymmetry, reproductive success and parasitism of Pomatoschistus microps in a French lagoon. J. Fish Biol. 57: 382-390.

Sommer, C. 1996. Ecotoxicology and developmental stability as an in situ monitor of adaptation. Ambio. 25: 375-376. 
Van Valen, L. 1962. A study of fluctuating asymmetry. Evolution, 16: 125-142.

Vøllestad, L.A., \& K. Hindar. 1997. Developmental instability and environmental stress in Salmo salar (Atlantic salmon). Heredity. 78: 125-222.

Vøllestad, L.A., \& K. Hindar. 2001. Developmental stability in brown trout: are there any effects of heterozygosity or environmental stress? Biol. J. Linn. Soc. 74: 351-364.
Waddington, C.H. 1942. Canalization of development and the inheritance of acquired characters. Nature (Lond.). 150: 563-565.

Wiener, J.G., \& P.J. Rago. 1987. A test of fluctuating asymmetry in bluegills (Lepomis macrochirus Rafinesque) as a measure of $\mathrm{pH}$-related stress. Environ. Pollut. 44: 27-36.

Zakharov, V. M., E. Pankakoski, B. I. Sheftel, A. Peltonen \& I. Hanski. 1991. Developmental stability and population dynamics in the common shrew, Sorex araneus. The American Naturalist. 138: 797810. 